\title{
BMJ Global Health Insulin price components: case studies in six low/middle-income countries
}

\author{
Douglas Ball, ${ }^{\oplus 1}$ Margaret Ewen, ${ }^{2}$ Richard Laing, ${ }^{3}$ David Beran ${ }^{\oplus} 4$
}

\begin{abstract}
To cite: Ball D, Ewen M, Laing $\mathrm{R}$, et al. Insulin price components: case studies in six low/middle-income countries. BMJ Global Health 2019;4:e001705. doi:10.1136/ bmjgh-2019-001705
\end{abstract}

\section{Handling editor Lei Si}

- Additional material is published online only. To view please visit the journal online (http://dx.doi.org/10.1136/ bmjgh-2019-001705).

Received 9 May 2019 Revised 21 July 2019 Accepted 27 July 2019
Check for updates

\section{C) Author(s) (or their} employer(s)) 2019. Re-use permitted under CC BY-NC. No commercial re-use. See rights and permissions. Published by BMJ.

'Public Health Pharmaceutical Consultant, Glasgow, UK ${ }^{2}$ Health Action International, Amsterdam, The Netherlands ${ }^{3}$ School of Public Health, Boston University, Boston, Massachusetts, USA ${ }^{4}$ Division of Tropical and Humanitarian Medicine, University of Geneva and Geneva University Hospitals, Geneva, Switzerland

Correspondence to Dr Douglas Ball; douglasball@yahoo.co.uk

\section{ABSTRACT}

Introduction Understanding price components for insulin products can help design interventions to improve insulin affordability in low/middle-income countries.

Methods An adapted WHO/Health Action International standardised methodology was used in Brazil (Rio de Janeiro), China (Hubei and Shaanxi Provinces), Ghana, India (Haryana State), Indonesia and Uganda. Selected insulin products had their prices traced backwards through the supply chain from public and private sector retail outlets in the capital city and a district town, supplemented with key informant interviews.

Results Cumulative mark-ups ranged from $8.7 \%$ to $565.8 \%$ but the magnitude of mark-ups was country specific and variable within and across sectors and regions. The proportion of the patient price attributed to the manufacturer's selling price varied from $15.0 \%$ to $92.0 \%$. Pricing regulations in China, India and Indonesia reduced wholesale and retail mark-ups but did not guarantee low prices. Most countries had removed import duties (Ghana, India, Indonesia, Uganda), but additional tariffs of $3.5 \%$ were still applied in Ghana. Value-added tax in the private sector ranged from $5 \%$ to $20 \%$ across the countries.

Conclusion There are no clear trends in the mark-ups applied to insulin or specific differences in the price structure. A uniform approach to improving insulin access through regulating price components is unlikely to be successful, but elimination of duties and taxes, price regulation and greater price transparency could help influence prices and hence affordability.

\section{INTRODUCTION}

Insulin is a life-saving medicine, yet access to it is poor especially in low/middle-income countries (LMIC). High prices are a key barrier for people needing insulin, ${ }^{1}$ particularly low wage earners. ${ }^{2}$ Insulin public procurement prices are high, have not fallen over time as with other medicines and some countries pay much higher prices than others. ${ }^{1}$ A survey across 43 countries in 2015 found that patient prices for human insulins were much lower than for analogues in both the public (median US $\$ 7.64$ vs US $\$ 45.03$ for $10 \mathrm{~mL} 100 \mathrm{IU} / \mathrm{mL}$ ) and private sectors (median $\$ 16.65$ vs $\$ 39.35$ ) with vials cheaper than pens and cartridges, but prices varied considerably between countries. ${ }^{2}$ Low-wage

\section{Key questions}

What is already known?

- Little is known about mark-ups and other add-on costs that contribute to the prices of medicines particularly in low/middle-income countries, and information available about other medicines may not be relevant to insulin, a biological product.

- Recent insulin price surveys under the Addressing the Challenges and Constraints of Insulin Sources and Supply study found that insulin prices can be very high, depending on the type, presentation and brand of insulin.

\section{What are the new findings?}

- Case studies of insulin price components, conducted in six low/middle-income countries, identified no systematic differences when comparing manufacturers, sectors, regions within the country, originator versus biosimilar products, human versus analogue insulin, or vials, cartridge or pens.

- Price regulation led to less variability in markups, but not necessarily lower prices, while import charges are still applied in some countries and value-added taxes are commonplace.

\section{What do the new findings imply?}

- While there is no clear uniform approach to regulating price components of insulin in order to increase access and affordability, the removal of tariffs and taxes would be beneficial and wider price regulation can be useful where resources for implementation, enforcement and price monitoring exist.

- Improved price transparency of insulin products will address information asymmetry in the market which affects patients and purchasers of healthcare.

workers would need about 3-10 days' wages to be able to purchase $10 \mathrm{~mL}$ of various insulin products. A more recent survey ${ }^{3}$ in 2016 in 13 LMICs found that government procurement prices of the same insulin product could vary substantially ( $\$ 1.45$ in Ethiopia vs $\$ 24.72$ in China for human isophane insulin), even when exactly the same brand (Lantus pen $\$ 21.56$ in Indonesia vs \$106.52 in China).

Studies in LMICs have found that government procurement policies, duties, taxes and supply chain issues are important barriers to 
insulin access. ${ }^{45}$ Understanding the components that make up the final price (including the manufacturer's selling price (MSP), wholesale and retail mark-ups, tariffs, taxes and other charges) may help identify means of improving efficiency and reducing prices within the supply system.

Health Action International (HAI) and the WHO have developed a standard methodology for examining price components through the use of case studies. ${ }^{6}$ Data from such studies for various medicines in LMICs show cumulative mark-ups between $11 \%$ and $6894 \%^{78}$ and have led to policy changes, such as a move to regressive mark-ups in Lebanon. ${ }^{9}$ However, price components specifically of insulin have not been studied and no other data are available. This paper presents a series of country case studies investigating insulin price components in selected LMICs as part of the Addressing the Challenges and Constraints of Insulin Sources and Supply (ACCISS) study in order to inform policy recommendations.

\section{METHODS}

The WHO/HAI methodology ${ }^{6}$ was adapted to only look at insulin products as described below. Six countries were purposively selected which had recently undertaken an insulin price and availability survey as part of the ACCISS study: Brazil (Rio de Janeiro Province), China (Hubei and Shaanxi Provinces), Ghana, India (Haryana State), Indonesia and Uganda.

The countries have varied health systems and approaches to insulin supply and pricing particularly in the public sector. In Brazil, human insulins are produced locally and are provided free in the public sector. However, imported analogue insulins may also be supplied and charged for. China caps public procurement prices and has recently instituted a zero mark-up policy for the public sector to replace a previous $15 \%$ mark-up. Patients may have to pay for insulin depending on their level of insurance and where they obtain their supply. There are local producers of biosimilar analogue insulins. In Ghana, all insulin is imported and public sector retail prices are set by the national health insurance (NHI) system. India has multiple producers of human and biosimilar insulin. Insulin specified on the national essential medicine list should be free in the public sector. Indonesia has universal NHI which sets procurement prices and distribution margins for insulins, which are all imported. Insulin is fully reimbursed under the health insurance. Uganda imports all insulin products which are provided free in the public sector. A brief summary of pharmaceutical policies in each country relevant to insulin is presented in online supplementary file 1 .

\section{Product and facility selection}

From the price and availability survey data, ${ }^{3}$ at least five insulin products were purposively selected based on availability, type (human, analogue and animal insulin), manufacturer and presentation. Thus, the survey included the most common products but also attempted to capture examples of analogue insulins and both vials and cartridges. If insulin glargine products were available, one was included in the data collection of the country. A summary of the insulin products surveyed $(100 \mathrm{IU} / \mathrm{mL}$ unless otherwise stated) is presented in online supplementary file 2 .

One public facility (main hospital) and the closest private retail facility were selected in the capital city ('Capital') and the main urban centre in a nearby district ('District'). Private hospital data were also collected in Indonesia (Capital and District) and Hubei Province, China (Capital).

\section{Data collection}

Data collection involved working back up the supply chain to identify the selling price at each stage (table 1) using standard forms. Data were collected first from the retailer, then the relevant wholesaler, and continued, where possible, to the port of entry for imported products, or the manufacturer for locally produced products. At each stage the key informant was informed of the purpose of the study, invited to participate and interviewed with documentary validation sought for prices. The pricing documentation could be in the form of paper or electronic invoices or price lists and depended on what was available at the facility on the day of visit as well as what the key informant was willing to share. In some cases, actual invoices of transactions were made available but this was not always the case. In addition, information about pharmaceutical policies and pricing was collected from relevant ministries and internet searches to inform interviews and triangulate findings. Where information or price data provided by key informants were not in agreement with these policies, the informants were asked

\begin{tabular}{lll}
\hline Table 1 & Price component 'stages' with examples \\
\hline Stage & Description & Sample price components \\
\hline 1 & MSP or CIF price & Manufacturer's price and freighting charges \\
2 & Landed cost & Banking, port clearance, inspection fees, import tariffs, importer mark-up/fee \\
3 & Wholesale & Overhead costs, storage charges, mark-up and local transport \\
4 & Retail & Overhead costs and mark-up \\
5 & Dispensed cost & Dispensing fee, sales tax/VAT \\
\hline
\end{tabular}

CIF, cost insurance freight; MSP, manufacturer's selling price; VAT, value-added tax. 
to clarify and additional checks were made to validate the price data and policy information. Insulin manufacturers were also provided with a draft of the report and given an opportunity to comment on the findings and make any clarifications.

Data collectors were experienced health professionals or academics who had participated in the previous price survey. They were trained in July 2016 and data collection took place during August to September 2016. Prices were entered into Excel workbooks with cleaning prior to analysis.

In Brazil, only one retailer and no wholesalers participated. Verified data were available down to wholesaler procurement level in all other countries except Ghana where wholesalers provided unvalidated prices only. In India (Haryana State) an unvalidated MSP was provided for one product. Where verified data were not available, MSPs and stage 1 (insurance and freight) and stage 2 (port clearance) costs were back-calculated based on publicly available information and interviews. The text refers to these back-calculated cases as 'estimated' costs or mark-ups. Local currency prices were converted to US \$ for indicative purposes (Oanda.com 13 November 2016).

\section{Statistical analysis}

The data are case studies, not a representative sample, preventing calculation of summary statistics. Therefore, only actual values and ranges are presented. Commonly surveyed products (insulin glargine and Humulin/ Huminsulin) were compared across countries.

\section{Patient and public involvement}

No patients or the general public were involved in the study.

\section{RESULTS}

The results are presented by supply chain stage (table 1 ), the total cumulative mark-up, their contribution to the final price and comparison of similar products. Summaries of mark-up levels and the contribution of all components to the final price are shown in online supplementary tables 1 and 2, with examples in figure 1 and online supplementary files 5 and 6 .

\section{Mark-ups by stage}

The magnitude of mark-ups was country specific. Pricing regulations shaped both public and private sector mark-ups in China (Hubei and Shaanxi), India (Haryana) and Indonesia and, except in Indonesia, tended to keep wholesale and retail mark-ups below those seen in Ghana and Uganda, although patient selling prices were not necessarily lower. Insufficient information was available to estimate stage 1 (shipping freight and insurance) costs except in Ghana (7\% public and private sectors) and Uganda (20\% private sector).

In China, import port clearance (stage 2) mark-ups incurred in both public and private sectors were about $33.5 \%$ (including $5 \%$ import duty, $17 \%$ value-added tax (VAT) and $8.7 \%$ importer mark-up) (online supplementary table 1). Estimated port clearance (stage 2) components in India added around $27 \%$ but this only affected the private sector since imported insulin products were not found in public facilities. The magnitude of the port clearance mark-up was similar to Indonesia although in the latter some were inflated (100\%-300\%) for non-NHI system patients. Port clearance costs were much lower in Ghana $(8 \%)$ and Uganda ( $0 \%$ public; $12 \%$ private) and generally the same for both public and private sectors. Ghana, India, Indonesia and Uganda had removed import tariffs on essential medicines including insulin,

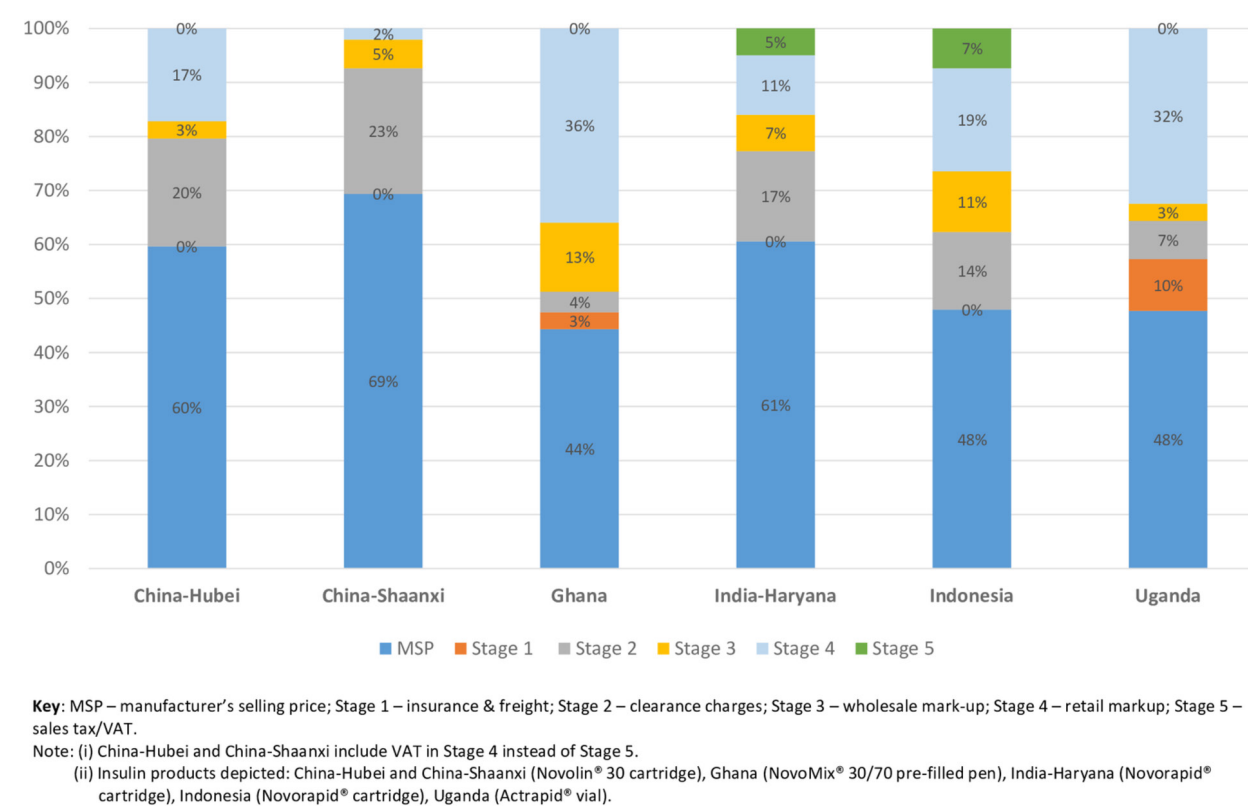

Figure 1 Examples of the contribution of mark-ups at various stages of the supply chain to the final price of typical insulin products in the private sector in six surveys across five countries. VAT, value-added tax. 
although in Ghana imported medicines still attracted an import levy (2\%) and a processing fee $(1 \%)$ among other charges.

Wholesale (stage 3) mark-ups varied within (depending on product, sector and district) and between countries. In China (Hubei), wholesale (stage 3) components were about $8.7 \%$ except for imported products in the private sector $(4.0 \%)$. More variability was seen in Shaanxi Province, with wholesale mark-ups ranging from $0.1 \%$ to $16.3 \%$ across public and private sectors with some remarkably low values, mostly in District facilities. No explanation for this was evident. In the Indian private sector, imported insulins in the private sector had wholesale mark-ups of $8.7 \%$ and domestically produced biosimilars attracted up to $11.1 \%$. In Indonesia, the mark-ups varied from $15 \%$ to $20 \%$ (including public and private sectors), but were higher in Ghana (25\%) and lower in Uganda ( $10 \%$ public, $5 \%$ private sector).

Retail (stage 4) mark-ups also varied. Hubei Province had instituted the national zero mark-up policy in the District public facilities, but Capital public facilities still added $15 \%-24 \%$. The public sector mark-up was $15 \%$ in Shaanxi Province which had not yet implemented the policy. Private sector retail mark-ups ranged from $4.5 \%$ to $20.7 \%$ (including VAT) in Hubei and from $2.1 \%$ to $35.5 \%$ in Shaanxi (including VAT). Facilities with markedly lower stage 3 mark-ups in Shaanxi sometimes had larger stage 4 mark-ups, but not consistently.

Stage 5 (sales tax/VAT) add-ons were wholly represented as VAT on the retail price in the private sector. Only Uganda exempted essential medicines from sales tax. India had the lowest VAT $(5 \%$ plus a $0.25 \%$ surcharge) followed by Indonesia (10\%), China (17\%; exempt at public or non-profit facilities), Ghana (17.5\% unless exemption claimed) and Brazil (20\%).

\section{Comparisons by product characteristics}

Comparison of price components for imported or domestically produced insulin products was limited since only China and India had significant use of the latter. However, the only difference noted was the application of port clearance (stage 2) charges for imported products. These products had essentially the same wholesale and retail mark-ups in Hubei Province in China as imported insulins, but in Shaanxi Province there was a more varied picture but with mark-up more frequently larger for biosimilars (eg, Basalin insulin glargine cartridge 11.8\% vs Lantus Solostar insulin glargine pen $5.3 \%$ wholesale mark-up in the public sector; $8.5 \%$ vs $5.7 \%$ retail in the private sector). In India the local products in the private sector attracted slightly larger wholesale $(11.1 \%$ vs $8.7 \%)$ and retail $(18.8 \%$ and $14.4 \%$ vs $13.1 \%)$ mark-ups.

Apart from the differential implementation of the zero mark-up policy in China (Hubei), mark-ups seldom varied systematically between Capital and District sites, and price regulations in India and Indonesia kept them similar at all sites (except two District facilities in Indonesia which levied high retail mark-ups on non-NHI patients). In Ghana, retail price components ranged from $23.9 \%$ to $56.1 \%$ (one outlier $131.2 \%$ where the pharmacy procured a particular insulin for one client) in the Capital and from $40.6 \%$ to $56.0 \%$ in the District. In Uganda, wholesale (stage 3) mark-ups were the same for both sites, but a more expensive product had a much lower retail mark-up (Actrapid vial MSP \$3.3, wholesale mark-up 5\%, retail mark-up $48 \%$, final price $\$ 7$ in both Capital and District; Mixtard 30 pen, MSP $\$ 5.6$ wholesale mark-up 5\%, retail mark-up $14 \%$, final price $\$ 9$ in District).

Public and private sectors had similar magnitudes of price components in China and Indonesia courtesy of price regulation (data from India were insufficient to compare). In Ghana, the wholesale mark-up was also the same in both sectors since they shared the same suppliers who charged the same to all clients. Public sector retail mark-ups were $43.6 \%$ (Capital) and $40.0 \%$ (District) for two products of similar MSP in the public sector and ranged from $23.9 \%$ to $56.1 \%$ (one outlier $131.2 \%$ ) in the private sector in Ghana.

Analogue insulin products generally had the same or similar mark-ups as human insulins and the same was true when comparing pens or cartridges and vials. Some variation was seen in the unregulated private sector in Ghana for the 'expensive' Lantus Solostar pen (insulin glargine). The same wholesale mark-up was applied for this product as to less costly human insulins $(25 \%)$ but in the District a higher retail mark-up (56\%) was applied than in the Capital (24\%) and this was also higher compared with human and isophane insulin products (range 33\%-56\%). This still resulted in a lower patient price (District \$25, Capital \$33) due to a much lower MSP (District \$11, Capital \$18), possibly due to an old procurement or procurement outside of usual supply chains.

\section{Cumulative mark-ups}

Across the surveys, cumulative marks-ups ranged from $8.7 \%$ to $47.7 \%$ for locally produced and from $10.0 \%$ to $565.8 \%$ for imported insulins (online supplementary table 1). This varied between countries with a complex picture in China. Public and private sectors are discussed together and were usually higher in the private sector.

In China (Hubei), public sector cumulative mark-ups ranged from $45 \%$ to $80 \%$ and were lower in the District than the Capital, for example, Humalog (lispro) cartridge costs US $\$ 10.90$ in the District public and private sectors ( $45.2 \%$ cumulative mark-up) but US $\$ 11.62$ (54.8\%) in the Capital private sector and US\$12.54 (67\%) in the Capital public sector. The cumulative mark-up was much lower for locally produced regular porcine insulin (9\%-25\%) with no port clearance (stage 2) costs and reduced VAT. However, in Shaanxi Province, locally produced insulin cumulative mark-ups ranged from $27 \%$ to $29 \%$ in the public and from $10 \%$ to $36 \%$ in the private sector. Public sector total mark-ups were higher than the private sector 
in the Capital, but the opposite was true in the District (except for insulin glargine).

In Ghana, the cumulative mark-up was around $100 \%$ in public and private sectors, with more variation in the private sector (range 92\%-126\%, one outlier 224\%), whereas in India (Haryana) imported products accrued around $65 \%$ but local products had cumulative mark-ups of $38 \%-48 \%$. In Indonesia, for NHI patients, the cumulative mark-up was in the range of $98 \%-111 \%$, but $98 \%-566 \%$ for non-NHI patients. In Uganda private sector cumulative mark-ups were $110 \%$ (Actrapid vial) and $61 \%$ (Mixtard prefilled pen).

\section{Contribution to final price}

The proportion of the final selling price attributed to the MSP varied from 15\% to 92\% (usually around 45\%-70\%), being higher for locally manufactured products. In Hubei, China, the MSP comprised 56\%-92\% of the final price, being largest for locally produced products that were only found in the public sector (online supplementary table 2; figure 1). The MSP contributed more in the District courtesy of the public sector zero mark-up policy. Similarly, in Shaanxi Province, the MSP contributed $56 \%-70 \%$ of the final price of imported products, slightly more in the private than the public sector, and was higher for local biosimilar products-around $78 \%$ in the public and $73 \%-91 \%$ in the private sector. Stage 2 costs made up about $20 \%$ of the final price of imported products in both provinces, and retail mark-ups about $13 \%$ in the public sector (varying between $2 \%$ and $26 \%$ in the private sector, with variation by region and origin of the product).

In Ghana, the MSP, wholesale (stage 3) and retail (stage 4) mark-ups contributed about half, $14 \%$ and $30 \%$, respectively, to public sector patient prices with a similar picture in the private sector. The MSP contribution was similar in Indonesia (50\%) except where large importer or retailer mark-ups were present (range 15\%-31\%). In Haryana, the MSP was $68 \%-72 \%$ of the final price for local biosimilars in both public and private sectors (see online supplementary table 2). For originator products, it was around $61 \%$ with port clearance (stage 2) costs $16.7 \%$ of the price for imports. In the Uganda private sector, the MSP was $48 \%$ of the final price for Actrapid (regular) vial with retail mark-up comprising 32\%. For Mixtard (isophane/regular mix) prefilled pen, the MSP contributed $62 \%$ and the retail mark-up $12 \%$.

\section{Comparison of Humulin and Huminsulin products}

Humulin/Huminsulin products (Eli Lilly) in Ghana, India (Haryana) and Indonesia across a variety of presentations and insulin mixes (table 2) showed national variations in the magnitude of mark-ups. Cumulative mark-ups varied from about $65 \%$ (Haryana) to $110 \%$ (Ghana) and from $260 \%$ to $565 \%$ in Indonesia (including non-NHI patients). The MSP was $47 \%$ of the final price in Ghana, $60 \%$ in Haryana and $15 \%-28 \%$ in Indonesia where port clearance (stage 2) costs predominated due to high importer mark-ups (figure 2).

Table 2 Comparison of mark-ups for Humulin/Huminsulin human insulin products in three countries

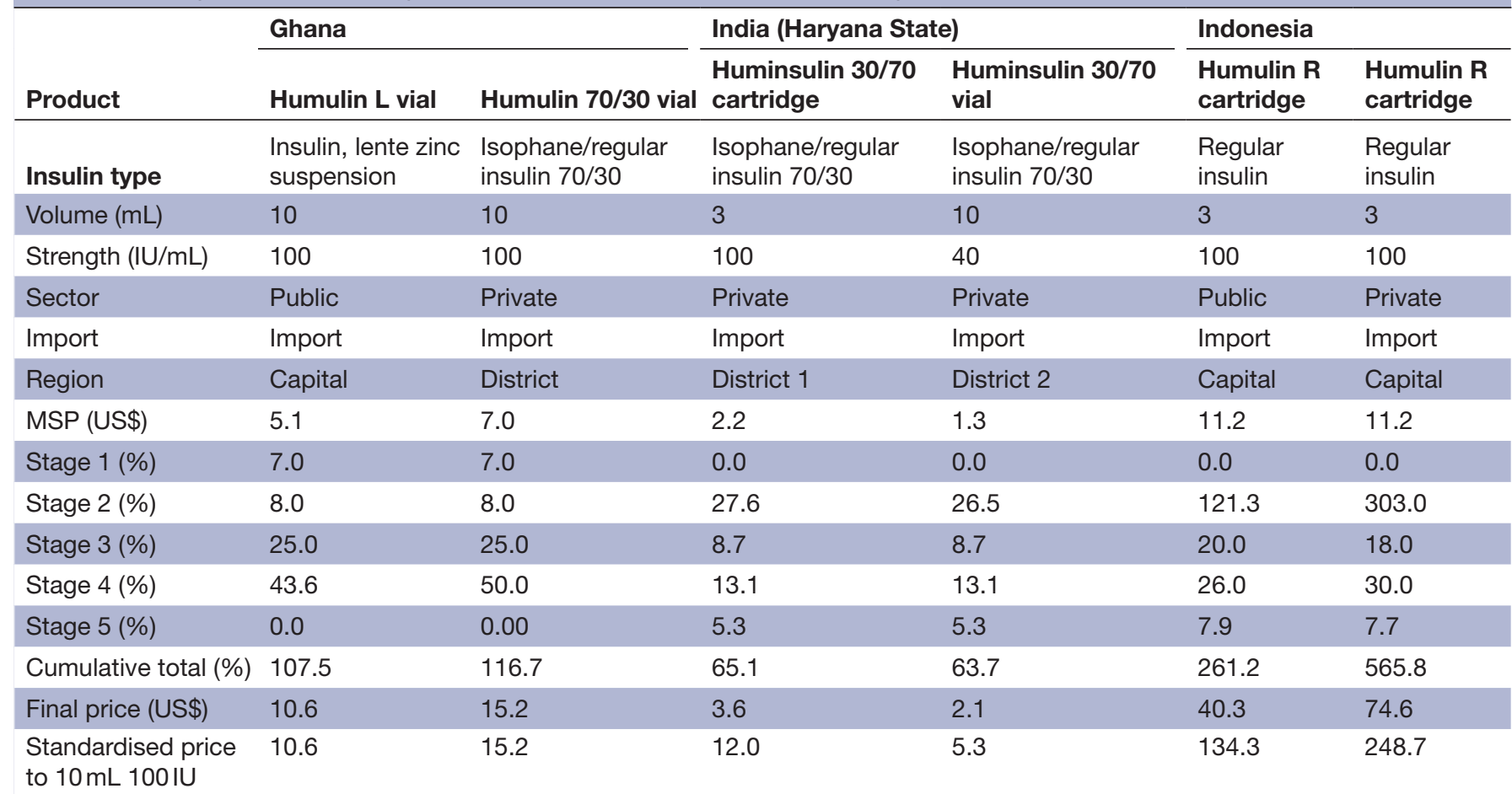

Stage 1: insurance and freight. Stage 2: clearance charges. Stage 3: wholesale mark-ups. Stage 4: retail mark-ups. Stage 5: sales tax/ value-added tax (VAT).

MSP, manufacturer's selling price. 


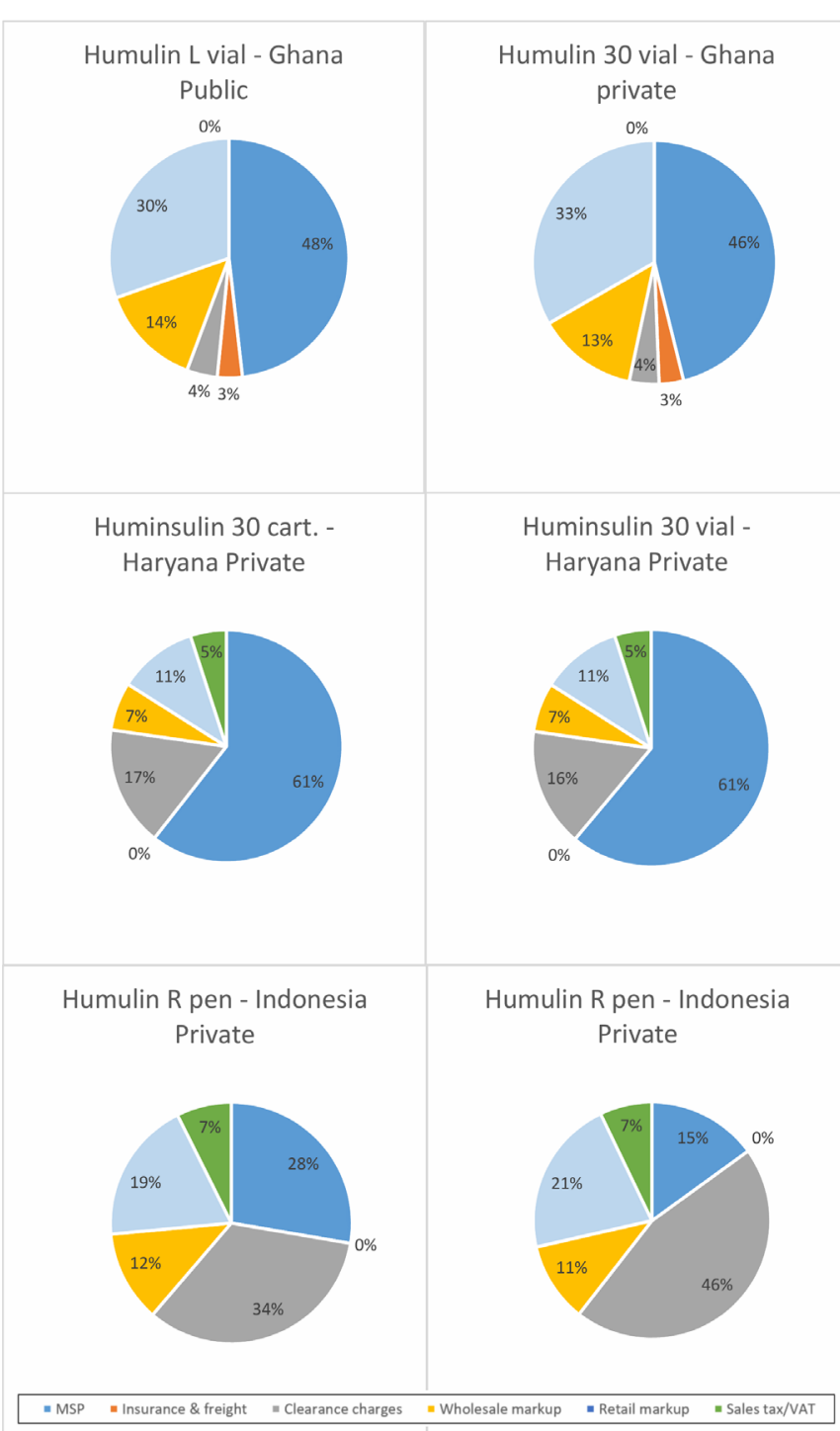

Key: MSP - manufacturer's selling price.

Figure 2 Contribution of mark-ups to final price for Humulin/Huminsulin products in three countries. VAT, valueadded tax.

\section{Comparison of insulin glargine products}

Four countries (five surveys) surveyed insulin glargine (table 3). Stage 2 (port clearance) charges added substantially to imported products, but distribution and retail mark-ups varied both between and within countries or regions with no common pattern.

\section{Other information}

Information supplied from key informant interviews indicated that discounts and trade schemes are used in the supply chain either from manufacturers or wholesalers. In Ghana, discounts (up to 20\%) offered by wholesalers to retailers depended on the quantities and payment terms, while in India invoices showed cash discounts on total invoice values (three cases; range 1\%-8\%) and one deal ( $10 \%$ free) with the benefits not passed on to insulin users.

\section{DISCUSSION}

This is the first paper to examine price components of insulin products across countries. While there are individual insights for each country, and limited data on price components from the Chinese surveys have been published as part of wider studies, ${ }^{10}{ }^{11}$ there were no systematic patterns in mark-ups when comparing manufacturers, sectors, regions, import or locally manufactured, type, or presentation of insulin.

Mark-ups were similar for locally manufactured insulins and imports. The MSP contributed a greater proportion of the final price of locally produced insulins due to the absence or reduction of stage 2 (port clearance) costs. Most of these examples came from India (Haryana) where private sector price regulation maintained similar wholesale and retail mark-ups for both local and imported products. In the private sector in China (Shaanxi), local products often had higher mark-ups than imported products showing that such mark-ups do not necessarily reflect actual costs. Indeed, lower cost items may need higher mark-ups to be sufficiently profitable. ${ }^{812}$

Both competition and price regulation can address MSPs (which constituted the bulk of many prices) as well as mark-ups. ${ }^{12}{ }^{13}$ While price regulation may play a role, it can be difficult to enforce in LMICs and may have unexpected detrimental effects if implemented inappropriately. ${ }^{78}$ Indonesia has price regulation with set e-procurement prices, wholesale and retail margins in both public and private settings for NHI patients. At some facilities, non-NHI patients were paying almost double for insulin due to 'unreasonable' mark-ups $(150 \%-200 \%)$ at the importer or retailer level. Until NHI coverage is universal, non-NHI patients need greater protection. Further investigation is required to explore the observation that price regulation did not necessarily result in lower patient prices, which could reflect low competition or poor procurement practices. Price monitoring and regular evaluation should support any pricing regulations.

The difficulty of enforcing price regulations was underlined by the slow implementation of the 2012 'zero mark-up policy' in the public sector in China which had only been implemented at the District sites in Hubei Province. Medicines are a major source of income for public health facilities in China ${ }^{11} 14^{15}$ and this may be the reason behind the slow implementation of the policy. This is complicated by fragmentation of policy implementation in public health facilities. ${ }^{11}$ The observation in China that prices for human and analogue insulins were somewhat similar and relatively high with mark-ups 'adjusted' to make up the differences may be a result of perverse incentives in regulations. A pricing regulation strategy incorporating international referencing could help address this. ${ }^{13}$

The results for India were similar to those reported by Sharma and Kaplan ${ }^{16}$ which is a reflection of the price regulations in place for distribution and retail mark-ups. However, there was a difference in the estimated port 
Table 3 Comparison of insulin glargine mark-ups between countries

\begin{tabular}{|c|c|c|c|c|c|c|c|c|c|}
\hline \multirow{3}{*}{ Import } & $\begin{array}{l}\text { China } \\
\text { (Hubei) }\end{array}$ & $\begin{array}{l}\text { China } \\
\text { (Shaanxi) }\end{array}$ & Ghana & & \multirow{3}{*}{$\begin{array}{l}\text { India (Haryana) } \\
\text { Lantus cartridge } \\
\text { Import }\end{array}$} & \multirow{2}{*}{\multicolumn{2}{|c|}{$\begin{array}{l}\text { Indonesia } \\
\text { Lantus Solostar pen }\end{array}$}} & \multirow{2}{*}{\multicolumn{2}{|c|}{$\begin{array}{l}\text { China (Shaanxi) } \\
\text { Basalin cartridge }\end{array}$}} \\
\hline & \multicolumn{4}{|c|}{ Lantus Solostar pen } & & & & & \\
\hline & Import & Import & Import & Import & & Import & Import & Local & Local \\
\hline Region & Capital & Capital & District & Capital & District & Capital & Capital & Capital & District \\
\hline Sector & Public & Public & Private & Private & Private & Public & Private & Public & Private \\
\hline MSP (US\$) & 20.7 & 21.4 & 10.8 & 18.4 & 4.9 & 22.1 & 22.1 & 20.2 & 20.2 \\
\hline Stage $1(\%)$ & 0.0 & 0.0 & 7.0 & 7.0 & 0.0 & 0.0 & 0.0 & 0.0 & 0.0 \\
\hline Stage $2(\%)$ & 33.5 & 33.5 & 8.0 & 8.0 & 27.6 & 26.8 & 182.0 & 0.0 & 0.0 \\
\hline Stage $3(\%)$ & 8.7 & 5.3 & 25.0 & 25.0 & 8.7 & 15.0 & 15.0 & 11.8 & 0.5 \\
\hline Stage 4 (\%) & 15.0 & 15.0 & 56.0 & 23.9 & 13.1 & 26.0 & 15.0 & 15.0 & 9.3 \\
\hline Stage $5(\%)$ & 0.0 & $0.0^{*}$ & 0.0 & 0.0 & 5.3 & 7.9 & 8.7 & 0.0 & $0.0^{*}$ \\
\hline $\begin{array}{l}\text { Cumulative total } \\
(\%)\end{array}$ & 66.9 & 61.6 & 125.4 & 79.0 & 65.1 & 98.3 & 305.4 & 28.6 & 9.8 \\
\hline Final price (US\$) & 34.5 & 34.5 & 24.7 & 32.7 & 8.0 & 43.8 & 89.5 & 26.0 & 22.2 \\
\hline
\end{tabular}

In some cases more than one glargine product was surveyed, but only a single representative product is shown unless major differences were evident. Note that some products are complete pens and others are cartridges.

Stage 1: insurance and freight. Stage 2: clearance charges. Stage 3: wholesale mark-ups. Stage 4: retail mark-ups. Stage 5: sales tax/ value-added tax (VAT).

*VAT incorporated in stage 4.

MSP, manufacturer's selling price.

clearance (stage 2) costs. In this survey, these were estimated at about $20 \%$ based on a single unverified MSP provided by a key informant and applied the same across all products. Sharma and Kaplan reported import to wholesale price mark-ups usually of the order of $11 \%-26 \%$ (with some as low as $5 \%$ and one outlier of $75 \%$ ).

There were seldom any differences in the mark-ups between District and Capital regions apart from a few country-specific findings, in contrast to previous work in Kyrgyzstan that showed wholesalers charging more for distant facilities. ${ }^{17}$ In the China (Shaanxi) public sector, Capital wholesale mark-ups pushed up total mark-ups particularly for locally manufactured products. Otherwise, wholesalers often charged the same percentage mark-up regardless of price in both public and private sectors. In Ghana's private sector, District retailers tended to have higher mark-ups which may reflect higher risk in carrying insulin stock. In general, retailer mark-ups varied considerably where the absence of regulations allowed. Dispensing fees were not used in any of the countries.

China and India did not have mark-up policies that favoured locally produced insulins. However, these products tended to be lower cost due to the absence of stage 2 costs. It was difficult to compare public and private sector pricing strategies since insulin was provided free of charge to patients in the public sector in most of the countries-although it was not necessarily available,${ }^{10}$ a common issue with public sector medicines in general. ${ }^{18}$ The MSP tended to contribute less to products procured by public tender in Ghana and Uganda, but these were products different from those available at private retailers. Private sector had greater variation in wholesale and retail mark-ups due to less regulation. The public sector wholesale (stage 3) mark-up in Ghana was $25 \%$ while in Uganda the National Medical Stores charged a flat $10 \%$ to cover port clearance (stage 2) and wholesale costs. Such charges vary widely between LMICs and within regions, ${ }^{7-9}$ and there is scope for reduction of public sector wholesaling charges as a means to reducing prices to insulin users.

Most studies were unable to identify the various port clearance (stage 2) charges. However, in Ghana, while insulin products were exempt from import duties (as in India, Indonesia, Uganda), they attracted $3.5 \%$ other charges including a 'special import levy', and other levies to support regional bodies, export development, and processing, in addition to port clearing and bank charges. Such 'hidden' charges have been identified in other countries on medicine imports, such as levies for the Standards Association and Ministry of Defence in Sudan. ${ }^{9}$ These can have a substantial effect on prices since they are incurred at an early stage of the supply chain.

In addition, all countries apart from Uganda charged some form of tax on sales of insulin, with mechanisms for VAT recovery by wholesalers in Ghana and Indonesia reportedly not used due to cumbersome procedures, and with no system to monitor if reduced costs from such exemption were passed on to insulin users. Reduced or eliminated taxes on insulin could result in lower prices in the private sector where many patients source their medicines due to poor availability in the public sector. ${ }^{13}$ 
Across the studies it was clear that there was a lack of transparency about prices, particularly the MSP but also at wholesale level. Discounts, rebates and other trade practices add to the confusion of pricing along the supply chain, benefiting suppliers without evidence of benefit to patients, something that has been addressed in South Africa by outlawing such deals. ${ }^{19}$ While recognising concerns about confidentiality of business practices, this also means that it is not possible for insulin users, government or insurers to know whether they are being charged a 'fair' price, especially in markets (such as the insulin market) where competition is limited. ${ }^{4}$

While these data only provide a snapshot of insulin price components in the various countries, the lack of systematic differences between price components of imported/domestically produced insulins, human/ analogue insulins and those sold in the capital compared with the district suggests that insulin products are generally supplied and priced in a manner similar to other medicines. An exception would be where insulin is exempted from import duty in Ghana (also no import duty in Uganda as an essential medicine). Studies of wholesale and retail mark-ups in pharmaceutical supply chains in LMICs are limited and have not shown any consistency, although flat percentage mark-ups tend to predominate in the public sector ${ }^{8}$ and probably also the private sector as shown by case studies in Ghana and Malawi ${ }^{20}$ and supported by this study. Only a few LMICs, such as Mali, have either regulated mark-ups or made exemptions from mark-ups or taxes for certain essential medicines, which may include insulin. ${ }^{820}{ }^{21}$ Mark-ups do not seem to vary by disease class, but rather mark-ups and prices are set in order to achieve an overall profitability for each of the players in the supply chain, at least in the private sector, taking into account international, national and local factors such as national pharmaceutical policy, supply chain constraints, business environment, market share, competition and demand, as has been described for antimalarial artemisinin combination therapies. ${ }^{22}$ This may mean that it may be difficult to promote 'insulin only' solutions in the private sector to improve access unless they are simple to implement in the local environment and make economic sense to supply chain actors.

\section{Limitations of the data}

Lack of information from manufacturers, importers and wholesalers meant that MSPs and port clearance (stage 2) costs were estimated based on interviews and publicly available information. Stage 2 costs were applied uniformly whereas they might vary depending on consignment value and other factors, meaning MSPs may show wider variability. Despite this, the use of verified field data allows for general impressions, trends and characteristics to be assessed in these six countries. The case study method is better suited for use by individual countries to examine their own situation and devise policy interventions. Only gross international trends would likely be observed between countries. International comparisons are also difficult due to the different insulin products surveyed in each country. However, this reflected the reality of use in the countries, and insulin glargine products were surveyed where available in order to facilitate international comparison.

\section{CONCLUSIONS}

The country case studies indicate no clear patterns in insulin price components, suggesting there is no one-sizefits-all approach. However, various country-specific issues needing intervention were identified. The removal of tariffs and taxes can help lower prices. Competitive public procurement can target high MSPs, but suppliers are limited. Price regulation (including regressive mark-up strategies) can address MSPs as well as mark-ups and may play a role, but needs to be supported with price monitoring, market surveillance and enforcement. Even so, opacity on true manufacturing costs can undermine such regulation. Transparency of insulin prices throughout the supply chain is needed but remains a challenge in countries.

Acknowledgements The work and inputs of the national investigators to collect and enter data, and review the findings, are gratefully acknowledged: Brazil (Rio de Janeiro): Vera Lucia Luiza; China (Hubei Province): Xinping Zhang and Chenxi Liu; China (Shaanxi Province): Yu Fang; Ghana: Charles Allotey; India (Haryana State): Girdhari Lal Singal; Indonesia: Yusi Anggriani; Uganda: Denis Kibira. Thank you to the insulin manufacturers who provided comments on the findings for their products.

Contributors All authors have contributed substantially to the study and manuscript. Concept: DBA, ME, RL. Design: DBE, ME. Data collection and analysis: ME, DBE. Manuscript writing: DBE. Critical review: DBA, ME, RL, DBE. All authors have given their final approval to the submission.

Funding This work was undertaken as part of the ACCISS study which is funded by The Leona M and Harry B Helmsley Charitable Trust and Stichting ICF.

Disclaimer The analysis included in this report is that of the authors alone and does not necessarily reflect the views of the Helmsley Charitable Trust or Stichting ICF. All references and conclusions are intended for educational and informative purposes and do not constitute an endorsement or recommendation from the Helmsley Charitable Trust or Stichting ICF.

Competing interests None declared.

Patient consent for publication Not required.

Provenance and peer review Not commissioned; externally peer reviewed.

Data availability statement Data are available upon reasonable request.

Open access This is an open access article distributed in accordance with the Creative Commons Attribution Non Commercial (CC BY-NC 4.0) license, which permits others to distribute, remix, adapt, build upon this work non-commercially, and license their derivative works on different terms, provided the original work is properly cited, appropriate credit is given, any changes made indicated, and the use is non-commercial. See: http://creativecommons.org/licenses/by-nc/4.0/.

\section{REFERENCES}

1. HAI. Insulin prices profile. Amsterdam: health action international, 2016. Available: http://haiweb.org/wp-content/uploads/2016/04/ ACCISS-Prices-report_FINAL-1.pdf [Accessed 1 Nov 2017].

2. Ewen $\mathrm{M}$, Joose $\mathrm{H}-\mathrm{J}$, Ashigbie $\mathrm{P}$, et al. Insulin prices profile. Amsterdam: Health Action International, 2017.

3. Ewen M, Joosse H-J, Beran D, et al. Insulin prices, availability and affordability in 13 low-income and middle-income countries. BMJ Glob Health 2019;4:e001410.

4. Beran D, Ewen M, Laing R. Constraints and challenges in access to insulin: a global perspective. Lancet Diab Endocrinol 2016;4:275-85. 
5. Beran D, Yudkin JS, de Courten M. Assessing health systems for type 1 diabetes in sub-Saharan Africa: developing a 'Rapid Assessment Protocol for Insulin Access'. BMC Health Serv Res 2006;6:17.

6. WHO/HAl. Measuring price components. In: Measuring medicine prices, availability, affordability and price components. 2nd Ed. Geneva: World Health Organization and Health Action International, 2008.

7. WHO/HAl. Regulation of mark-ups in the supply chain. pharmaceutical pricing policies and interventions. policy brief No. 3, Amsterdam: health action international, 2014. Available: http:// haiweb.org/wp-content/uploads/2015/08/3_WHOHAI_Policy-Brief_ Mark-ups 2015.pdf [Accessed 1 Jun 2017].

8. Ball DE. The regulation of Mark-ups in the pharmaceutical supply chain. WHO/HAI project on medicine prices and availability review series on pharmaceutical pricing policies and interventions working paper 3, 2011. Available: http://haiweb.org/what-we-do/priceavailability-affordability/resources-for-pricing-policies/ [Accessed 1 Jun 2017].

9. Ball DE, Mirza Z, Ewen M. Medicine prices, availability, affordability and price components: a synthesis report of medicine price surveys undertaken in selected countries of the who eastern Mediterranean region. Cairo: WHO, 2007.

10. Li Z, Feng Q, Kabba JA, et al. Prices, availability and affordability of insulin products: a cross-sectional survey in Shaanxi Province, Western China. Trop Med Int Health 2019;24:43-52.

11. Liu C, Zhang X, Liu C, et al. Insulin prices, availability and affordability: a cross-sectional survey of pharmacies in Hubei Province, China. BMC Health Serv Res 2017;17:597.

12. Dukes MNG, Haaijer-Ruskamp FM, de Joncheere CP, et al. Drugs and money: prices, affordability and cost-containment. Geneva: WHO, 2003.

13. World Health Organization. WHO guideline on country pharmaceutical pricing policies. Geneva: WHO, 2015.
14. Sun J, Hu CJ, Stuntz M, et al. A review of promoting access to medicines in China - problems and recommendations. BMC Health Serv Res 2018;18:125.

15. Fang Y. Chapter 9. Pharmaceutical Policy in China. In: Babar Z, ed. Pharmaceutical policy in countries with developing healthcare systems (ISBN 978-3-319-51672-1). Cham: Springer, 2017.

16. Sharma A, Kaplan WA. Challenges constraining access to insulin in the private-sector market of Delhi, India. BMJ Glob Health 2016;1:e000112.

17. Waning B, Maddix J, Soucy L. Balancing medicine prices and business sustainability: analyses of pharmacy costs, revenues and profit shed light on retail medicine mark-ups in rural Kyrgyzstan. BMC Health Serv Res 2010;10:205.

18. Cameron A, Ewen M, Ross-Degnan D, et al. Medicine prices, availability, and affordability in 36 developing and middle-income countries: a secondary analysis. The Lancet 2009;373:240-9.

19. Suleman F, Gray A. Chapter 14. Pharmaceutical Policy in South Africa. In: Babar Z, ed. Pharmaceutical policy in countries with developing healthcare systems (ISBN 978-3-319-51672-1). Cham: Springer, 2017.

20. McCabe A, Seiter A, Diack A, et al. Private sector pharmaceutical supply and distribution chains: Ghana, Mali and Malawi. health systems for outcomes publication 53107. world bank Africa region health systems for outcomes program, 2009. Available: http:// documents.worldbank.org/curated/en/745621468270302773/ pdf/531070WP0Pharm10Box345597B01PUBLIC1.pdf [Accessed Accesed Jun 2019].

21. Maïga D, Maïga S, Maïga MD. Processus et enjeux de la réglementation des prix des médicaments essentiels dans le secteur pharmaceutique privé au Mali [Process and issues in the regulation of prices of essential medicines in the private pharmaceutical sector in Mali]. Med Trop 2010;70:180-4.

22. Palafox B, Patouillard E, Tougher S, et al. Prices and mark-ups on antimalarials: evidence from nationally representative studies in six malaria-endemic countries. Health Policy Plan 2016;31:148-60. 